\title{
Return to the Basics: Examination for Birefringence and Its Direction Is Critical to Diagnosis of Gout
}

\author{
Bruce M. Rothschild
}

check for updates

Citation: Rothschild, B.M. Return to the Basics: Examination for Birefringence and Its Direction Is Critical to Diagnosis of Gout. Rheumato 2021, 1, 2-4. https:// doi.org/10.3390/rheumato1010002

Received: 25 October 2021 Accepted: 26 October 2021 Published: 27 October 2021

Publisher's Note: MDPI stays neutral with regard to jurisdictional claims in published maps and institutional affiliations.

Copyright: (C) 2021 by the author. Licensee MDPI, Basel, Switzerland. This article is an open access article distributed under the terms and conditions of the Creative Commons Attribution (CC BY) license (https:/ / creativecommons.org/licenses/by/ $4.0 /)$.
Department of Medicine, Indiana University School of Medicine, IU Health, Indianapolis, IN 46202, USA; spondylair@gmail.com

In the spirit of initiating a new journal for Rheumato, it is pertinent to review the attention to the basics that first established the field as an evidence-based approach to recognition and treatment of arthritis and multisystem diseases and the reputation of its disciples as resources for solving diagnostic dilemmas. The ensuing decades have witnessed substantial incursions on our ability to continue to utilize some of the approaches that have served us and our patients so well. This has led to proposition of diagnostic shortcuts [1]. One section of Rheumato will include examination of proposed alternatives and review the underlying basics upon which our approaches have been based. We start with an entity (gout) that Rheumato may consider quite straight-forward, an entity for which we still seem to be that not-so-still small voice crying out in the wilderness.

Should gout be diagnosed solely on the basis of history, physical examination and serum uric acid level? Is synovial fluid examination essential? What do routine X-rays contribute? These are the issues fundamental to recognition of gout (and somewhat of pseudogout) critical to appropriate intervention.

Podagra is the phenomena classically attributed to gout [2]. That approach initially seemed reasonable, but was challenged with recognition [3] that other disorders occasionally cause first metatarsal phalangeal joint inflammation-but, how often? Is this a significant source of misdiagnosis? During my residency in internal medicine, acute podagra was observed as a common occurrence in patients hospitalized in the intensive care unit. The perspective at that time was that gout was responsible, secondary to fluid shifts related to the treatment of the hospitalization-requiring event. Since infection was always a possibility, I routinely aspirated the affected joint. Imagine my surprise to find positively birefringent calcium pyrophosphate crystals in 24 of 25 patients.

That, however, is only the tip of the iceberg with respect to confusion associated with attempts to diagnose gout. Low dose aspirin-containing medications represent commonly utilized over-the-counter products that have pertinent pharmacodynamics. While high dose aspirin may facilitate uric acid excretion, low dose aspirin impedes excretion, resulting in hyperupricemia [3]. Therefore, hyperuricemia is not diagnostic of gout, but rather suggests the likelihood of patient ingestion of low dose aspirin, alcohol, or of a diuretic such as hydrochlorthiazide - which increases uric acid resorption in the kidney [4,5]. And, of course, not all patients with gout have hyperuricemia [3]. Additionally, it must be recalled that it is not levels, but acute changes in uric level that precipitate and aggravate gout attacks - so introduction of or alteration of allopurinol dose is of course contraindicated.

Those experiences flavored my diagnostically nihilistic attitude towards diagnosing gout solely on the basis of "gout scores" incorporating only history, physical examination and serum uric acid levels [1], at the expense of crystal documentation or the presence of classic radiologic signs. The latter can be challenging, as typical gouty erosions do not have the diagnostic overhang sign. The classic alteration is uncommon, although the presence of soft tissue densities may facilitate diagnosis of gout, with pseudogout (calcium pyrophosphate deposition disease) also requiring consideration. 
How should crystal examination be performed, by whom, and when (related to the timing of aspiration (obtaining the sample))? Lessing and colleagues [6] appropriately emphasize the importance of synovial fluid aspiration (arthrocentesis) or mass (e.g., tophus) aspiration and polarizing microscopic evaluation of that fluid for crystals in order to validate gout and pseudogout diagnoses. This is, of course, in addition to gram stain and culture, as the presence of either crystal does not actually exclude a septic arthritis diagnosis [3]. Uric acid precipitation as monosodium urate crystals is quite $\mathrm{pH}$ - and temperature-sensitive $[7,8]$. The latter is perhaps responsible for the generally acral distribution (e.g., resulting in podagra) of disease, while the reduction in $\mathrm{pH}$ (acidification) associated with infected synovial fluid results in loss of solubility of concentrations of uric acid that would otherwise not precipitate [8]. Uric acid crystals also salt out (precipitate) as a phenomenon secondary to the synovial fluid acidosis of pyogenic arthritis.

However, it is also the temperature effects that suggest the value of review of physical chemistry characteristics and their implications. Reduction in synovial fluid temperature from in vivo $37^{\circ} \mathrm{C}$ to that on a slide at ambient temperature $\left(32^{\circ} \mathrm{C}\right)$ also reduces both uric acid and calcium soluability [7], resulting in monosodium urate and calcium phosphate deposition, the latter in the form of star-shaped brushite crystals. If the fluid is not examined in a timely manner (or purposely delayed), the associated temperature reduction allows precipitation of uric acid as monosodium urate crystals. This is directly related to the duration of temperature reduction $[9,10]$. Wet mounts (sealing the slide) may prevent false positive calcium crystal deposition but will not obviate false positive gout diagnosis. Of course, histologic handling of specimens requires modification of standard technique to assure all processing is anhydrous, in view of the water solubility of gout crystals-which usually do not survive routine preparation approaches [3].

It is said that Winston Churchill had 100 new ideas a day; three were good. He had excellent advisors. While polarizing examination of fluid or tissue for crystals, utilizing a compensator to distinguish urate and calcium pyrophosphate crystals appears critical to accurate gout diagnosis [11], acceptance of routinely postponing crystal examination [6] or even avoiding it entirely [1], are ideas whose time has not yet come.

Conflicts of Interest: The author declares no conflict of interest.

\section{References}

1. Neogi, T.; Jansen, T.L.; Dalbeth, N.; Fransen, J.; Schumacher, H.R.; Berendsen, D.; Brown, M.; Chjoi, H.; Edwards, N.L.; Janssens, J.J.; et al. 2015 gout classification criteria: An American College of Rheumatology/European League Against Rheumatism collaborative initiative. Ann. Rheumatic Dis. 2015, 74, 1789-1798. [CrossRef] [PubMed]

2. McCarty, D.J.; Hollander, J.L. Identification of urate crystals in gouty synovial fluid. Ann. Intern. Med. 1961, 54, 452-460. [PubMed]

3. Rothschild, B.M. Gout and pseudogout. Medscape Rheumatol. 2021. Available online: http://emedicine.medscape.com/article/32 9958 (accessed on 26 October 2021).

4. Choi, H.K.; Atkinson, K.; Karlson, E.W.; Willett, W.; Curhan, G. Alcohol intake and risk of incident gout in men: A prospective study. Lancet 2014, 363, 1277-1281. [CrossRef]

5. Duskin-Bitan, H.; Cohen, E.; Goldberg, E.; Shochat, T.; Levi, A.; Garty, M.; Krause, I. The degree of asymptomatic hyperuricemia and the risk of gout. A retrospective analysis of a large cohort. Clin. Rheumatol. 2014, 33, 549-553. [CrossRef] [PubMed]

6. Lessing, J.N.; Matias, P.C.; Pierce, R.G. A tincture of time-Latent crystal formation and clinical decision-making in acute gout. A teachable moment. JAMA Intern. Med. 2016, 17, 165-166. [CrossRef] [PubMed]

7. Dieppe, P.; Hornby, J.; Swan, A.; Hutton, C.; Preece, A. Laboratory handling of crystals. Ann. Rheumatic Dis. 1993, 42 (Suppl. S1), 60-63. [CrossRef]

8. Martillo, M.A.; Nazzal, L.; Crittenden, D.B. The crystallization of monosodium urate. Curr. Rheumatol. Rep. 2014, 16, 400. [CrossRef]

9. Font, F.; Goldman, J.; Toro, R. Monosodium urate crystals (MSUC) and spherulites (SP) in asymptomatic metatarsophalangeal (MTP) joints. Arthritis Rheumatol. 1982, 25, 53.

10. Yuan, S.; Bien, C.; Wener, M.H.; Simkin, P.; Rainey, P.M.; Astion, M.L. Repeat examination of synovial fluid for crystals. Clin. Chem. 2003, 49, 1562-1563. [CrossRef]

11. Oliviero, F.; Scanu, A.; Galozzi, P.; Gava, A.; Frallonardo, P.; Ramonda, R.; Punzi, L. Prevalence of calcium pyrophosphate and monosodium urate crystals in synovial fluid of patients with previously diagnosed joint diseases. Jt. Bone Spine 2013, 80, 287-290. [CrossRef] [PubMed] 


\section{Short Biography of Author}

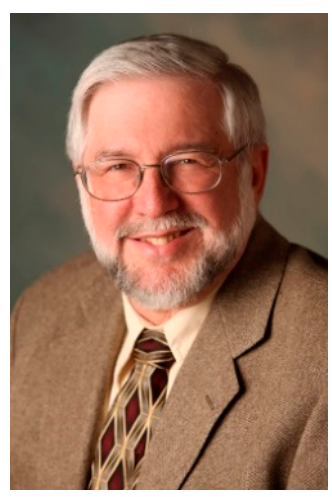

Bruce M. Rothschild graduated from New Jersey College of Medicine in 1973. He is a member of the Society of Vertebrate Paleontology, Fellow of the American College of Physicians, American College of Rheumatology and Society of Skeletal Radiology and elected to the International Skeletal Society. He has been recognized for his work in Rheumatology and Skeletal Pathology where his special interests focus on clinical-anatomic-radiologic correlation, data-based paleopathology, evolution of inflammatory arthritis and tuberculosis and management of inflammatory arthritis. He is widely recognized for his contributions to understanding radiologic manifestations of rheumatologic disease. He has been a Visiting Professor at universities in the US, Canada, the Caribbean, South America, Europe, the Middle East, South Africa, Asia and Australia and has been an invited lecturer at universities, hospital and museums throughout the world. He has published over 1000 papers and abstracts, including authoritative papers on the origins of rheumatoid arthritis, spondyloarthropathy, syphilis and tuberculosis, character of bone changes in metastatic cancer, myeloma, leukemia, tuberculosis, fungal disease, renal disease, treponemal disease, rheumatoid arthritis, spondyloarthropathy, gout, calcium pyrophosphate deposition disease, hypertrophic osteoarthropathy and primate bone disease. $\mathrm{He}$ is the author of 7 books and has participated in 8 Discover Channel/BBC documentaries on origins of diseases and ancient reptiles.

Since 1986, Dr. Rothschild has been Professor of Medicine at Northeast Ohio Medical University in Rootstown, Ohio, West Virginia University and Indiana University Health and holds Research Associateship at the Carnegie Museum. He was first director of the Rheumatology Division at The Chicago Medical School and a prime force behind the resurgence of data-based paleorheumatology and comparative osseous pathology. 